\title{
OTIMIZAÇÃO DE PROCESSOS POR MEIO DA ENGENHARIA REVERSA
}

Letícia Marin da Silva (Centro Universitário Farias Brito - FBUni) leticiamarin@outlook.com Mauricio Johnny Loos (Centro Universitário Farias Brito - FBUni) mauricioloos@ hotmail.com

\section{Resumo}

O presente trabalho é colocado como um mecanismo de instrução e apresenta, de forma objetiva, o papel da engenharia reversa. São apresentadas as técnicas relacionadas que podem ser utilizadas na sua implementação, bem como os pontos favoráveis e dificuldades envolvendo o conceito. Essa pesquisa foi estruturada através de uma pesquisa ação em uma empresa de refrigeração de grande porte, que buscou a engenharia reversa como base para o desenvolvimento de um produto e assim conseguir atender uma demanda atípica. Em consequência dessa aplicação, a empresa conseguiu atingir melhorias no processo.

Palavras-Chaves: Engenharia Reversa, Otimização de Processos.

\section{Introdução}

Desde a Revolução Industrial, o desenvolvimento tecnológico foi se aperfeiçoando em um intervalo curto de tempo. Esse progresso vem servindo como auxílio para melhorar os processos da produção e atrair maior demanda, consequentemente, a empresa que investe na evolução tecnológica se torna mais competitiva e garante a sua permanência no mercado (CARDOSO, 2007).

O interesse das empresas para permanecerem competitivas se expandiu demasiadamente, buscando lançar novos produtos cada vez mais inovadores. Os lançamentos envolvem todos os setores e modelos buscando atender diversos clientes através da mudança das cores, tamanhos, diferenciações de capacidade, embalagens, etc. É notória a redução da eficiência do produto, a cada dia novos produtos são introduzidos no mercado, tornando os antecedentes ultrapassados na sua categoria (LEITE, 2009).

Dias (1998), enfatiza a importância da inovação tecnológica nas empresas direcionando-as a serem mais competitivas e pontua que a imitação exerce uma função importante na propagação desse progresso, o que impulsiona os líderes a buscarem novos caminhos.

A engenharia reversa se encontra entre os métodos fundamentais no que se diz respeito ao desenvolvimento e adequação do produto. Em referência a adequação, a ER visa o aperfeiçoamento de um produto através de outro já disponível para consumo, porém esse conceito não é muito explorado por ser confundido com pirataria ou com cópia do produto. No entanto, a aplicação desses conceitos demanda conhecimentos do objeto em estudo, para 
assim trabalhar juntamente com o desenvolvimento do processo, no qual apresentam certa complexidade (MURY e FOGLIATTO, 2001).

Esse conceito permite que peças sejam reproduzidas e complementadas, propondo redução de custos e inclusão de atributos requisitados pelos clientes. A aplicação dessa metodologia pode ter uma participação significativa no desenvolvimento de países com economia em ascensão, principalmente para os que possuem um progresso satisfatório em seu parque industrial. Ela é utilizada como ferramenta de apoio e cria oportunidades em mercados específicos através dessas modificações, capacitando as empresas desses países a ofertarem o que o consumidor necessita (MURY e FOGLIATTO, 2001).

O artigo propõe esclarecer os princípios da Engenharia Reversa, bem como os benefícios e complexidades. O trabalho não apresenta apenas a imitação de um produto, mas sim o desenvolvimento e confecção de um produto superior com melhorias, através de passos metodológicos e a verificação da aplicação em um estudo de caso com bons resultados.

O trabalho adota a pesquisa ação como abordagem metodológica. Para cumprir seus objetivos, o trabalho primeiramente estabelece o referencial teórico, seguido pelos procedimentos metodológicos adotados, análise dos resultados obtidos e, finalmente, suas conclusões.

\section{Revisão da literatura}

$\mathrm{Na}$ revisão teórica abordaram-se informações relevantes sobre o conceito e os passos metodológicos da Engenharia Reversa.

\subsection{Engenharia reversa}

Na concepção de Mury e Fogliatto (2001), a origem do termo Engenharia Reversa não é conhecida e o seu uso é limitado devido as dificuldades para se obter as informações necessárias da peça em análise. Porém a partir dos anos 90, essa técnica começou a ser mais difundida devido à diminuição do ciclo de vidas dos produtos, consequentemente obrigando as empresas a se tornarem cada vez mais ágeis no desenvolvimento de seus produtos. O termo é definido pela desconstrução do objeto, a fim de determinar todos os passos do seu desenvolvimento (MELLO et al., 2011). Na sequência, Mello et al. (2011) aborda que a engenharia reversa destaca-se por realizar a cópia de outros produtos. Os pontos críticos referem-se às especificações do produto, quando se aplica a ER ainda sim é necessário 
investimento na área de pesquisa e desenvolvimento do produto; e planejamento do processo produtivo, uma vez que é importante conhecimento na área para realizar a série de montagem e durante a aplicação da ER essas informações não são facilmente identificadas. Deste modo o processo de ER promove obtenção do conhecimento através de uma parte, ou um conjunto relevante do produto, que permita reproduzi-la considerando técnicas de produção mais adequadas, aborda Souza (2007).

A divulgação dessa técnica fica comprometida por ser considerada muita das vezes como pirataria, porém a ER pode proporcionar aos países em crescimento um desenvolvimento tecnológico, já que possibilita adaptações nos produtos quase que de imediato aos pedidos realizados pelos clientes. A prática da ER nesses países oferece a oportunidade de adequar produtos que anteriormente eram destinados a um tipo de mercado (MELLO et al., 2011).

A ER difere em algumas etapas do desenvolvimento de produto convencional, já que no primeiro caso utiliza-se como base um produto projetado e no segundo caso a criação do produto surge de uma ideia nova. Caso a necessidade do cliente não seja verificada, através de uma pesquisa, a ER é aplicada visando a réplica do objeto. Mas se essa necessidade for aprofundada com pontos de melhorias identificados, o uso da ER se torna uma ferramenta de auxílio para execução dessas modificações (MURY e FOGLIATTO, 2001).

Segundo Mello et al. (2011), na fase de desenvolvimento do produto a ER pode ter dois posicionamentos, focar as atividades e tecnologias na cópia do produto presumindo que nenhuma alteração será necessária ou utiliza-se essa metodologia como reprojeto de produtos, cujo suporte é voz do consumidor, desenvolvendo um produto apropriado para o cenário do mercado atual. Para Dias (1998), a empresa que escolhe a utilização da ER como caminho de desenvolvimento de um novo produto, utilizando outro como modelo a ser seguido, está exposta a vantagens e desvantagens em relação a custos e benefícios. Os riscos, tempo de desenvolvimento e custos envolvidos em um projeto em que se tem um produto como referência são bem menores em relação ao um produto original, sem privilégios de informações. Essa prática reduz significativamente os custos, pois mesmo quando há necessidade de realizar estudos esse valor é bem menor se for comparado a um estudo de um produto legítimo visto que o número de tentativas para a resolução de um problema seria inferior, por outro lado o risco legal é elevado significativamente. 


\subsection{Passos metodológicos da engenharia reversa}

Conforme Mury e Fogliatto (2001), a metodologia apresentada é composta por oito passos: Coleta de Dados, Engenharia Reversa, QFD (Desdobramento da Função Qualidade), Viabilidade Financeira, Prototipagem, Qualidade, Implementação, e Análise de Resultados, conforme ilustrada na figura 1 . O primeiro passo não pesquisa diretamente com a demanda quais as necessidades de mudança, mas busca as informações com a demanda que procura essas mudanças. Essas informações são alcançadas pelo especialista no mercando, dessa forma o investimento em pesquisas de mercado é reduzido. Mury e Fogliatto (2001) ressaltam que essas demandas também podem ser representadas pelas empresas encarregadas a introduzir o produto no mercado, e as informações adquiridas são descritas como especificações técnica do produto, preço alvo, custo de frete e impostos para cálculo do preço DDP do produto (Delivered Duty Paid - preço posto no estabelecimento do cliente com os custos de importação incluídos). A qualidade dessas informações determinará, principalmente, o bom resultado da utilização da ER. No segundo passo, Engenharia Reversa, utiliza-se a metodologia a fim de captar em outros produtos a particularidade que se pretende reproduzir. Na hipótese de aplicar a ER sem o interesse de incrementar o novo produto, é utilizada como recurso para estudar o produto atual e buscar o aprimoramento do mesmo, eliminando possíveis irregularidades. Nessa etapa os produtos são desmontados, suas peças são detalhadas e listadas, os materiais utilizados são analisados e aproveita-se para elaborar os desenhos das peças. Logo após, é realizada uma comparação entre os dois produtos através de uma tabela, e os pontos de melhoria são determinados (MURY e FOGLIATTO, 2001). A terceira etapa une os requisitos de qualidade buscados pelo cliente e os apresentados pelo fabricante para iniciar a montagem da matriz qualidade, dessa forma é possível focar em qual processo é mais importante e necessita de um acompanhamento maior a fim de assegurar a qualidade final do produto. Segundo Mury e Fogliatto (2001), sobre a Viabilidade Financeira pode-se concluir que todo investimento aplicado na modificação necessita ser amortizado. Para que seja possível comprovar os ganhos desse projeto, vários pontos relacionados ao investimento são observados, uma vez que se observados separadamente expresse inviabilidade. No quinto passo realiza-se um protótipo do produto, no qual deve ser semelhante ao produto final, visto que serão utilizados pelos clientes como amostragem até que o produto final seja disponibilizado. Durante a confecção desses protótipos não se espera que se tornem perfeitos, mas que sejam apresentados como modelos bem próximos do produto final. 
Após os clientes serem apresentados aos protótipos e passarem por um processo de avaliação dos mesmos, é realizada uma verificação no processo de manufatura do produto buscando manter o nível de qualidade apresentado ao cliente através do protótipo. Através dessa quantidade de amostras é realizado um levantamento dos principais defeitos encontrados e frequência de ocorrências, desenvolvendo a matriz de defeitos do produto. O seu objetivo é rastrear o processo envolvido na manufatura e classificar o seu nível gerador de defeitos. Para os principais processos causadores são elaboradas cartas de controle, buscando identificar operações desnecessárias ou que possam ser melhoradas. Durante a implementação do produto, sétima etapa, os produtos são modificados, assim como o processo de fabricação. As principais dificuldades dessa fase estão relacionadas a manufatura: geralmente quando os pedidos são realizados em pequenas quantidades não se tem muita flexibilidade de confecção, um maquinário exclusivo para o processo, consequentemente aumentando o tempo de setup. Nessa fase o critério de inspeção é mais rigoroso, impossibilitando um aumento de produção, como resultado os custos de produção sofrem um acréscimo. Outro ponto nessa fase é quando há dificuldade em adquirir um ferramental automatizado, criando processos manuais e aumento da mão-de-obra. E por último tem-se a análise dos resultados, sendo que nessa fase são apresentadas as dificuldades encontradas durante a aplicação da metodologia e os resultados adquiridos. Ela possui duas fases: a primeira além de apresentar as dificuldades enfrentadas busca revelar a flexibilidade da empresa em relação à mão-de-obra e área técnica na absorção desses novos processos. A segunda fase está relacionada ao contato com o cliente durante a negociação, a busca do feedback por parte do consumidor tende a melhorar o entendimento quanto à necessidade e expectativa empregada a negociação (MURY e FOGLIATTO, 2001). 
Figura 1- Esquema genérico do modelo de desenvolvimento dos produtos.

- Especificações técnicas do cliente.

\section{Coleta de Dados}

- Dados financeiros e logísticos sobre o produto.

- Características de qualidade demandadas/verificadas pelo cliente com sua respectiva priorização.

- Amostras físicas do produto atualmente comercializado.

\section{Engenharia Reversa}

- Desmontagem do produto e criação da tabela de componentes.

- Análise dos materiais empregados.

- Geração de desenho técnico com medidas de ambos produtos, concorrente e próprio.

- Tabela comparativa entre os produtos, formação de especificações e benchmarking.

- Identifícação dos componentes a serem modificados

4. Viabilidade Financeira

- Avaliação financeira do processo de adaptação do produto.

5. Prototipagem

- Desenvolvimento de protótipos com as alterações efetuadas.

\section{Qualidade}

- Montagem da Folha de Inspeção e da Matriz dos Defeitos.

- Elaboração de cartas de processo.

- Análise das falhas com o uso do FMEA.

\section{QFD}

- Montagem da Matriz da Qualidade com a priorização dos Itens de Qualidade Demandada e as respectivas Características da Qualidade.

- Elaboração das Matrizes de Produto e Processos para determinar os componentes e processos prioritários.

\section{Análise dos Resultados}

- Avaliação dos obstáculos enfrentados e dos resultados obtidos visando novos processos de adaptação de produtos.

Fonte: MURY e FOGLIATTO (2001).

\section{Procedimentos metodológicos}

O artigo foi estruturado por meio da metodologia de pesquisa-ação, uma vez que o pesquisador se encarrega de realizar a pesquisa e atuar como participante (FRANCO, 2005). Na sequência, Franco (2005) conceitua que essa forma de pesquisa direciona a transformação de uma realidade, e requer o envolvimento de todos responsáveis pelo processo. Mello (2012) ressalta que essa metodologia gera conhecimento através da prática. A criação desse conhecimento e a transformação da realidade ocorrem ao mesmo tempo, de acordo com a influência recíproca dos mesmos. 
A aplicação do conceito apresentado foi realizada em uma empresa responsável pela produção de refrigeradores comerciais do tipo plug-in e está entre as líderes no mercado. As suas atividades envolvem a montagem de produtos verticais e horizontais, de diferentes modelos e aplicações para diversos produtos como sorvetes, bebidas e congelados. A empresa possui forte aliança com as maiores redes varejistas do Brasil e atende ao mercado na América do Sul. Um dos países importadores com alto volume é a Bolívia, e os produtos destinados a esse país possuem uma particularidade dos demais. As portas que possuem visores de vidro, exportadas para esse país em especial, devem conter uma válvula de escape dentro da montagem, para saída do gás injetado. Essa peça é inserida para evitar que o conjunto de vidro estoure durante o transporte, devido à variação de pressão entre os dois países.

A montagem desses pacotes é constituída por lâminas de vidro que são separadas por um espaçador de alumínio. Dentro desse espaçador é realizada a injeção de sílica para absorver qualquer umidade dentro da montagem. A união dos vidros com o espaçador ocorre devido aplicação de uma borracha butílica entre as peças. Essa substância é conhecida por realizar o primeiro selo e também é responsável por reter o gás injetado dentro do conjunto montado, correspondente ao seu alto nível de impermeabilidade aos gases e o ar. Após a montagem do pacote é aplicado um silicone estrutural em todo o seu contorno, conforme figura 2.

Figura 2 - Vidro Insulado.

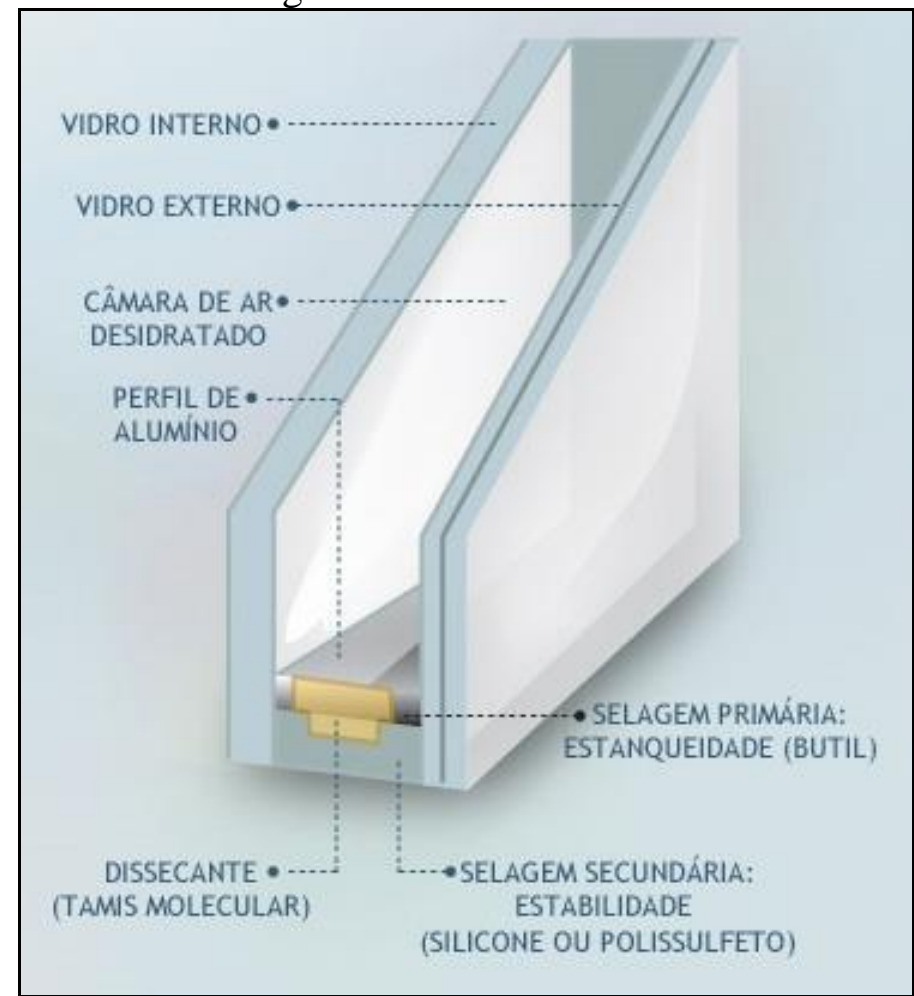

Fonte: Site Catálogo de Arquitetura 
No caso das portas, desses produtos enviados à Bolívia, devem conter essa válvula que possibilite o escape do gás, e é posicionada na face superior do pacote. Todavia a empresa de refrigeração não dominava o processo de fabricação desses pacotes com a inserção da válvula, portanto foi desenvolvido um fornecedor especializado para fabricação das portas prontas. A porta completa contempla o pacote descrito, um quadro de molduras de PVC (Policloreto de vinila) no contorno do pacote, puxador, borracha de vedação entre a porta e o batente do gabinete, e o limitador de abertura.

Quando eram programados esses produtos de exportação, o procedimento era posicionar a porta no produto e somente quando a porta estivesse "de pé" a válvula poderia ser aberta, já que durante o transporte dessas portas compradas até o último manuseio as peças vinham deitadas e dessa maneira o gás escaparia por completo do pacote se a válvula estivesse aberta. Por essa razão a válvula deveria permanecer fechada até o posicionamento da porta no produto.

Após o posicionamento da porta, é efetuada a abertura da válvula. Como ela fica posicionada no pacote de vidro e a moldura é acoplada por cima do conjunto, existe um alívio na moldura para que se tenha acesso a peça. Essa abertura se deve ao desrosquear a peça em algumas voltas, garantindo que o gás escape até igualar a pressão interna do pacote com o ambiente externo, assim que o cliente receber o produto ele possui uma instrução para fechar essa válvula rosqueando-a até o final.

Em um determinado ano, o país importador gerou uma demanda para os próximos três meses bem maiores do que o de costume, e nesse período a empresa fornecedora das portas com válvula não conseguiria entregar a quantidade solicitada. Como efeito disso, a equipe de engenharia responsável por essa montagem, se reuniu em busca de uma solução para essa nova demanda. O primeiro passo foi aplicar a engenharia reversa com as portas fornecidas pela empresa, sendo que as peças foram desmontadas e as novas peças (válvulas) foram analisadas, bem como analisados os possíveis processos utilizados para essa fabricação.

Após a análise, a equipe listou as peças que seriam necessárias e os processos que deveriam ser desenvolvidos para replicar a mesma montagem. Com o auxílio de um operador que já havia trabalhado na empresa fornecedora, ele descreveu o processo de montagem do pacote de vidro. Logo se concluiu que como haviam algumas diferenças entre as montagens das empresas, o processo escolhido por aquela empresa estudada não seria necessariamente o melhor processo para a empresa com o projeto em desenvolvimento. Além de a montagem ter um nível de dificuldade maior, seria necessária a aquisição de dois novos equipamentos: para 
realizar o alívio na moldura de PVC e realizar o alívio no perfil de alumínio, uma vez que no caso estudado a válvula era aplicada no interior do perfil de alumínio.

Nessas condições foi pensado em outro processo que demandaria menos recursos e garantia sua qualidade. Pensou-se em substituir a válvula que era composta por uma porca, anel o'ring, e um parafuso Philips por um rebite tubular, anel o'ring e um parafuso Philips. O rebite foi posicionado no perfil de alumínio pela parede externa, com auxílio de um gabarito que garanta a sua posição, e fixado com uma supercola. Em seguida o operador realiza a aplicação do silicone estrutural no contorno do pacote, com atenção em especial no ponto onde a válvula foi fixada, dado que o silicone deve ser aplicado no contorno da válvula para melhorar a sua fixação e garantir a vedação da montagem. Após a aplicação do silicone deve-se esperar o tempo de cura do produto para continuar o processo. No próximo passo pega-se o pacote com o tempo de cura correto e realiza-se um alívio na primeira parede do perfil de alumínio, com auxílio de uma furadeira, sendo esse alívio o local onde o gás irá escapar caso a válvula esteja aberta. Porém, após a realização do alívio, é rosqueado o parafuso no rebite travando a saída do gás e finaliza-se a montagem da porta com válvula. Para validação do funcionamento da válvula foram aplicados diversos testes de estanqueidade para verificar se o gás realmente estaria escapando pela válvula quando aberta e sem o escape quando estivesse fechada.

\section{Apresentação e discussão de resultados}

Neste caso, com o estudo realizado na porta do fornecedor identificou-se alguns processos que seriam utilizados por eles e que não seriam facilmente implementados, mas que ainda assim foi possível absorver a ideia e aplicar o conceito, sem demandar tanto tempo quanto o de um desenvolvimento original. Com os processos que foram empregados houve o aproveitamento da mão-de-obra do setor, aumentando a eficiência em $20 \%$. Esses processos desenvolvidos foram de fácil aplicação, todos os recursos utilizados na execução foram obtidos internamente e não contabilizados, pois não demandaram investimento significativo.

Se o projeto fosse apenas replicar a ideia do fornecedor seria necessária a aquisição de pelo menos dois maquinários, no entanto devido à mudança da estratégia conseguiu-se eliminar a precisão de um equipamento e adaptar outro dispositivo já utilizado em processos normais de linha. Através dessa adaptação foi possível produzir o alívio na moldura de PVC, para que o cliente tenha acesso à válvula. $\mathrm{O}$ equipamento, que já era operado pelo setor, reproduz o desenho projetado em um gabarito para a peça plástica. 
Anteriormente, uma porta que era comprada a um custo elevado passou a custar um terço desse valor inicial. Logo, a empresa líder no segmento e que é fortemente cobrada por redução de custos, obteve um lucro, no primeiro ano, por volta de trezentos mil reais. Com impacto desse caso, outros produtos começaram a ser analisados a fim de aplicar a metodologia reversa e buscar internalização dos processos.

Assim, vale ressaltar que o projeto abordado nesse trabalho buscou o atendimento da demanda, devido ao alto grau de competitividade no mercado, mas alcançou também o aprofundamento técnico e oportunidades de otimização de processos.

\section{Conclusões}

O caso retratado aponta mais um exemplo prático utilizando o conceito da Engenharia Reversa, oferecendo juntamente a sua definição teórica. De fato, através desse trabalho constatou-se que com a aplicação desse processo é possível obter resultados positivos.

A empresa objeto de estudo, optou pela aplicação dessas técnicas como um passo estratégico diante da falta de capacidade oferecida pelo seu fornecedor. Por meio da análise realizada, pode-se notar que o método de montagem e materiais utilizados pelo fornecedor não possuía o processo ideal se fosse aplicado com as mesmas características na empresa. Porém, em resposta a esse problema, ficou clara a flexibilidade da empresa para absorção de processos que até pouco tempo eram desconhecidos. Ainda que o projeto mensurasse os ganhos que seriam obtidos nessa primeira demanda, o retorno anual superou a expectativa.

\section{REFERÊNCIAS}

BARTZ, D.; STAUDT, T.; DE SOUZA, M. A.. Gestão estratégica de custos: uso da engenharia reversa na análise dos custos de concorrentes. Revista Base (Administração e Contabilidade) da UNISINOS, v. 2, n. 3, p. $167-175,2005$.

CARDOSO, S. R. ADISSI, P. J. XAVIER, L. H. XAVIER, V. A. Ciclo de Vida do Produto, Tecnologia e Sustentabilidade: Breve Análise da Gestão Ambiental de Resíduos Sólidos no Brasil. XXVII ENEGEP. Foz do Iguaçu, 2007.

Catálogo de Arquitetura. Em:< http://catalogodearquitetura.com.br/insulado.html >. Acesso em 20 de Junho de 2017.

DIAS, A. B.. Engenharia Reversa: uma porta ainda aberta. Produto \& Produção, Porto Alegre, v. 2, n. 1, p. $1-7,1998$. 
FRANCO, S.; AMÉLIA, M.. Pedagogia da pesquisa-ação. Educação e pesquisa, v. 31, n. 3, 2005.

LEITE, P. R. Logística Reversa: Meio Ambiente e Competitividade. $2^{\text {a }}$ Ed. São Paulo: Pearson Prentice Hall, 2009.

MELLO, C. H. P. et al. Pesquisa-ação na engenharia de produção: proposta de estruturação para sua condução. Production, v. 22, n. 1, p. 1-13, 2012.

MURY, L. G. M.; FOGLIATTO, F. S.. Adaptação de produtos para mercados diferenciados a partir da engenharia reversa. Production, v. 11, n. 2, p. 5-22, 2001.

RAJA, V. Introduction to reverse engineering. Reverse Engineering, p. 1-9, 2008. 